\title{
QUEEN'S
UNIVERSITY
BELFAST
}

\section{Evaporative Moisture Loss from Heterogeneous Stone: Material- Environment Interactions During Drying}

McAllister, D., Warke, P., McCabe, S., \& Gomez-Heras, M. (2016). Evaporative Moisture Loss from

Heterogeneous Stone: Material- Environment Interactions During Drying. Geomorphology, 273, 308-322.

https://doi.org/10.1016/j.geomorph.2016.08.008

\section{Published in:}

Geomorphology

\section{Document Version:}

Peer reviewed version

\section{Queen's University Belfast - Research Portal:}

Link to publication record in Queen's University Belfast Research Portal

\section{Publisher rights}

(c) 2016 Elsevier B. V. This manuscript version is made available under the CC-BY-NC-ND 4.0 license

$\mathrm{http}: / /$ creativecommons.org/licenses/by-nc-nd/4.0/,which permits distribution and reproduction for non-commercial purposes, provided the author and source are cited.

\section{General rights}

Copyright for the publications made accessible via the Queen's University Belfast Research Portal is retained by the author(s) and / or other copyright owners and it is a condition of accessing these publications that users recognise and abide by the legal requirements associated with these rights.

Take down policy

The Research Portal is Queen's institutional repository that provides access to Queen's research output. Every effort has been made to ensure that content in the Research Portal does not infringe any person's rights, or applicable UK laws. If you discover content in the Research Portal that you believe breaches copyright or violates any law, please contact openaccess@qub.ac.uk. 
1 Evaporative Moisture Loss from Heterogeneous Stone: Material2 Environment Interactions During Drying

3

4 Daniel McAllister ${ }^{1}$, Patricia Warke ${ }^{2 *}$, Stephen McCabe ${ }^{3}$ \& M. Gomez-Heras ${ }^{4}$ 5

6

$7{ }^{1}$ The Dow Chemical Company - Belfast, Northern Science Park, Belfast BT3 9DT, 8 United Kingdom,

92 School of Geography, Archaeology \& Palaeoecology, Queen's University Belfast, 10 Belfast BT7 1NN, United Kingdom

$11{ }^{3}$ Northern Ireland Environment Link, 89 Loopland Drive Belfast BT6 9DW, United 12 Kingdom

134 CEl Moncloa (UPM, UCM, CSIC): ETS Arquitectura (UPM) and Instituto de 14 Geociencias (CSIC, UCM), Madrid, Spain

16 *Corresponding Author: Patricia Warke - p.warke@qub.ac.uk 


\section{Abstract}

2 The complexities of evaporation from structurally and mineralogically heterogeneous sandstone (Locharbriggs Sandstone) are investigated through a laboratory-based experiment in which a variety of environmental conditions are simulated. Data reported demonstrate the significance of material-environment interactions on the spatial and temporal variability of evaporative dynamics. Evaporation from porous stone is determined by the interplay between environmental, material and solution properties, which govern the rate and mode by which water is transmitted to, and subsequently removed from, an evaporating surface. Initially evaporation is marked by high rates of moisture loss controlled by external atmospheric conditions; then, when a critical level of surface moisture content is reached, hydraulic continuity between the stone surface and subsurface is disrupted and the drying front recedes beneath the surface, evaporation rates decrease and are controlled by the ability of the material to transport water vapour to the surface. Pore size distribution and connectivity, as well as other material properties, control the timing of each stage of evaporation and the nature of the transition.

These experimental data highlight the complexity of evaporation, demonstrating that different regions of the same stone can exhibit varying moisture dynamics during drying and that the rate and nature of evaporative loss differs under different environmental conditions. The results identify the importance of material-environment interactions during drying and that stone micro-environmental conditions cannot be inferred from ambient data alone.

23 These data have significance for understanding the spatial distribution of stone weathering-related morphologies on surfaces in both the natural and built environments and may provide a clearer explanation for the initiation and subsequent development of weathering forms such as individual hollows and honeycomb-like networks of hollows (tafoni).

Keywords: evaporation, sandstone, porosity, permeability 


\section{$1 \quad 1.0 \quad$ Introduction}

2 There are a variety of ways in which moisture can enter porous stone but there is 3 only one mechanism by which it can leave and that is by evaporation (Hall and Hoff 2012). Evaporation from porous media embodies the interaction between temperature and moisture, variables that are interdependent and fluctuate simultaneously (Hall and Allinson 2010a, 2010b). More specifically, evaporation involves the simultaneous transfer of heat and mass with latent and/or sensible heat fluxes linked to the liquid-gas phase change that is necessary for water to leave porous stone (Brüggerhoff et al. 2001; Prommas 2011). Evaporation is typically associated with the process of drying through the reduction in bulk moisture content that accompanies moisture egress. But, quite apart from drying, evaporation mediates the rate of water exchange between stone and the external environment. Evaporation thus plays a key role in the moisture dynamics and water balance of stone but it is a complex process, operating in three-dimensional space in response to internal capillary gradients and external short-term changes in environmental conditions at the stone / air interface.

Recognition of the complexity of moisture dynamics within stone is essential for better understanding of the mechanisms of deterioration, which, for the most part, depend on available moisture for their effective operation (e.g. Goudie and Viles 1997; Bland and Rolls 1998; Whalley and Warke 2005; Smith 2012). Currently, the detail of moisture movement within stone is not fully understood with the number of studies focusing on this being limited and often related to the impact of externally derived agents such as salt. In particular there is a dirth of research investigating the factors controlling the removal of moisture from stone. In addition, sample homogeneity has been emphasized in experimental design, which is at odds with the structural and mineralogical complexity that is an inherent characteristic of the majority of stone types - characteristics that are often identified as being the key to explaining the initiation and development of complex weathering morphologies without the empirical evidence to support it. This was highlighted by Smith et al. (2008) who stress the role of meso-scale heterogeneity in giving rise to divergent patterns of weathering response.

Even the most structurally and mineralogically homogeneous stone contains microscale differences that can alter the rate at which moisture is initially taken up and 
1 subsequently released. For example, complexity may be introduced by the presence

2 of certain minerals such as clays, which are slow to release moisture because of 3 molecular electro-static bonds. Understanding the basic mechanics of moisture evaporation from porous media has improved in recent decades in line with technological advances that allow more accurate measurement of moisture content and temperature and the development of software that enables modeling of the changing distribution of moisture within porous material overtime (e.g. WUFI: Sass 2005).

9 This paper focuses on the hydraulic motions, differences and possible interactions that occur during evaporation from porous sandstone using an experimental approach to explore the material-environment interactions that can result in the creation of complex, and spatially variable, evaporative dynamics over a relatively small scale (centimeter and sub-centimeter).

The aim of this work is twofold;

1. To demonstrate that different regions of the same block of stone can experience different temperature and moisture conditions related to microscale features with the implication that evaporative response cannot be inferred from ambient data alone.

2. Exploration of the implications of data reported for better understanding the spatially variable nature of stone weathering phenomena.

\subsection{Methodology (Methods and Materials)}

The experiments presented here consider the spatially and temporally variable rates of evaporation from a heterogeneous porous stone. This work is shaped by the work of Lehmann and Or (2009) and Shahraeeni and Or (2010) which investigate evaporative dynamics from artificially controlled heterogeneous porous materials. These model porous materials composed of well-sorted sands with carefully determined grain size variations that are much simpler than the complicated geometries of natural porous stone (c.f. Yiotis et al. 2012).

The work presented here is not designed to validate numerical simulations, like these previous studies; but rather, it intends to provide preliminary experimental insights 
1 into the varying rate of evaporation from bedded, porous sandstone under different

2 simulated environmental conditions.

\subsection{Material Characteristics}

A block of Locharbriggs Sandstone $(14.0 \times 10.5 \times 2.4 \mathrm{~cm})$ was used in this study of the influence of structural variability on the nature and rate of evaporation. Locharbriggs Sandstone is a New Red Sandstone of Permian age (300-250Ma); it is quarried in the Dumfries and Galloway area of southwest Scotland. This porous (18.2-24.0\%), fine- to medium-grained, red-brown sandstone is shown in thin-section to be cemented by overgrowths of silica and hematite (Marica et al. 2006), with the latter giving the stone its characteristic red/brown colour. It is composed of sub- to well-rounded quartz grains and contains well-defined bedding structures with concentrations of clay minerals. Locharbriggs Sandstone is well known for its planar bedding, with these beds typically exhibiting both grain size and mineralogical variation (Hyslop and Abornoz-Parra 2009; Warke and Curran 2010).

The sample used in this study was specifically selected because of its marked heterogeneity with three beds clearly distinguishable in hand specimen exhibiting varying grain-size characteristics (Bed B: medium; Bed A: fine-medium and Bed C: fine-grained). An overview of the structural and mineralogical properties of Locharbriggs Sandstone is provided in Table 1a with detail of the pore characteristics of each of the three beds outlined in Table $1 \mathrm{~b}$ and Figure 1. Porosity characteristics were obtained from Mercury Intrusion Porosimetry (MIP) with an Autopore IV 9500 Micrometrics mercury porosimeter. The pore size interval characterisation ranged from 0.001 to $1000 \mu \mathrm{m}$, which corresponds to the highest and lowest pressure heads. MIP was performed on a small irregular block sample, approximately $6.5 \mathrm{~cm}^{3}$, taken from each of the three beds of the same sample source as the experimental block.

Wet and dry images of the three beds are shown in Figures $2 a$ \& b with Figure 2c showing the two-dimensional planar surface area of each bed in the experimental block which was calculated using ImageJ 1.46r image processing software.

30 The block was sealed on five sides with a plastic paraffin laboratory film used to 31 restrict the evaporation of moisture through one block face $\left(14 \times 10.5=147 \mathrm{~cm}^{2}\right)$. The 
1 selected block face displayed visible bedding and thus more closely reflected

2 conditions experienced by a normally bedded section of stone or stone block.

3 Permeability measurements were taken using an unsteady-state portable probe permeameter (PPP 250TM, Core Laboratories, Houston, USA). Unsteady-state permeametry computes the gas (air) permeability of porous materials by measuring the pressure decay as a function of time of pressurized air, which has been forced through the stone surface (McKinley et al. 2006).

The PPP 250TM has an aperture radius of $8 \mathrm{~mm}$ and permeability measurements were taken following a regular grid with a $1 \mathrm{~cm}$ sample spacing - the edges of the block were not sampled to reduce interference related to edge effects (Figure $2 \mathrm{~d}$ ). This produced 120 measurements for the exposed stone surface. Because the measurement aperture radius of $8 \mathrm{~mm}$ was almost equivalent to the sample spacing, consecutive measurements were taken at non-contiguous points on the sampling grid (see McKinley et al. 2006) to reduce the influence of residual gas from previous permeability measurements. Summary statistics and histograms, were produced for the bulk surface; permeability readings were also divided by bed type and mapped using OriginPro 8 to reveal any variability related to diagenesis.

\subsection{Monitoring Evaporation}

20 During experimentation evaporation was monitored using a combination of weight change and imaging techniques. For the former, weight change data were collected using a Gibertini EU-1000 (Gibertini Elettronica Srl., Milan) electronic balance, with an accuracy of $0.01 \mathrm{~g}$. The latter involved the use of several cameras, a digital camera and two infrared cameras.

The digital camera was used to image the stone surface at times of observable surface change. Two infrared cameras were used to monitor the temperature of the exposed stone surface. The first, a FLIR ThermaCAM B4 (FLIR Systems, Massachussets) was used to manually acquire thermal images of the stone surface at specified intervals. This camera has a thermal sensitivity of $0.1^{\circ} \mathrm{C}$ at $30{ }^{\circ} \mathrm{C}$. It is equipped with a Focal Plane Array (FPA), uncooled microbolometer that operates in

31 the thermal radiation range of 7.5 to $13 \mu \mathrm{m}$ (long wave infrared radiation) mounted as a $320 \times 240$ pixel detector array. The field of view of the lens at minimum focal length 
$1(300 \mathrm{~mm})$ is $45^{\circ} \times 33^{\circ}$. The acquired thermal images were analysed using FLIR

2 ThermaCAM researcher.

3 The second thermal camera, an Optris Pl160 (Optris $\mathrm{GmbH}$, Berlin) high-speed

4 thermal video camera (capable of resolving change at $120 \mathrm{~Hz}$ ), was also used to

5 monitor stone surface temperatures. This thermal camera is also based upon an

6 uncooled FPA microbolometer with a spectral bandwidth of 7.5-13 $\mu \mathrm{m}$ - the detector,

7 however, is limited to $160 \times 120$ pixels. The camera was fitted with a $23^{\circ} \times 17^{\circ}$ lens.

8 Infrared imaging permits insights into the spatial variation in evaporative flux through

9 monitoring the spatial variation of temperature change across the material surface.

10 Infrared thermography is a novel technique that has successfully been applied in the

11 context of porous materials, investigating evaporation from, for example: artificial 12 soils (Shahraeeni and Or 2010, 2011; Nachson et al. 2011), concrete (Barreira and 13 de Freitas 2007) and natural porous stone (Gayo et al. 1996; Grinzato et al. 2011).

\subsection{Experimental Set-Up}

The Locharbriggs stone block was placed on an electronic mass balance. The thermal cameras were mounted on a tripod and positioned orthogonal to the stone block (Figure 3). The FLIR thermal camera lens was located $300 \mathrm{~mm}$ from the stone surface; the instantaneous field of view (IFOV), or pixel size, for this arrangement was $0.7 \mathrm{~mm}$. The Optris Pl160 was located $400 \mathrm{~mm}$ from the Locharbriggs sample resulting in an IFOV of $1 \mathrm{~mm}$.

The sample surface emissivity $(\varepsilon)$ was fixed to 0.95 on both thermal cameras. This value was determined empirically by adjusting the emissivity value on the camera until the temperatures registered matched those of a dry Locharbriggs sample held at $40{ }^{\circ} \mathrm{C}$ in an oven. The surface emissivity of materials may change with changing surficial moisture content (Camuffo 1998); this is not accounted for in the experimental design. Because of the orthogonal viewing angle, the influence of surface moisture on material emissivity is assumed to be negligible; the emissivity is $\varepsilon=1-$ reflectivity, and the reflectivity of water is $\sim 2.5 \%$ at normal incidence (this increases exponentially with viewing angle, Camuffo 1998).

31 The Locharbriggs sample and mass balance were surrounded above, behind and on 
1 each side by cardboard to reduce the effect of thermal reflections from the

2 surrounding laboratory environment whilst still allowing the capture of thermal images

3 of the stone surface.

4 The experiment involved simulating environmental conditions that stone is likely to 5 frequently experience, these are:

- Shade - achieved by leaving the stone to dry under laboratory conditions (Figure 3A)

- Surface airflow - achieved by using a desk fan, inclined at $28^{\circ}$ to the horizontal and placed at a distance of $360 \mathrm{~mm}$ from the test block (Figure 3B)

- Radiative heating - this was simulated using a 500W halogen lamp, inclined at $62^{\circ}$ to the horizontal and placed at a distance of $400 \mathrm{~mm}$ from the stone surface (Figure 3C)

- Radiative heating with a surface airflow - a combination of Figures 3B \& $3 \mathrm{C}$ was used to achieve these conditions (Figure 3D).

\subsection{Experimental Regime}

Before each experimental run the test block was immersed in a bath of water for a period of 14 hours. In this way, the Locharbriggs sample was allowed to absorb water freely under normal atmospheric pressure. Stone in the natural and built environments is rarely if ever in a state of complete saturation (c.f. Hillel 1998; Pender 2004) and even under conditions of high moisture content air will be distributed in discontinuous pockets within the pore system - a process referred to as air trapping (Hall and Hoff 2012).

The water bath and stone block were held at room temperature until experimentation commenced. The laboratory ambient conditions of temperature, relative humidity and pressure were recorded (Table 2). Differences in ambient conditions between experimental runs were relatively small and, although they are likely to affect the rate of evaporation, their influence is assumed to be negligible; the simulated effects of wind and solar heating are likely to offset the influence of these minor ambient variations. 
1 The wet-bulb temperature was calculated using the measured ambient (dry-bulb)

2 temperature, relative humidity and pressure. The wet-bulb temperature is commonly

3 referred to as the temperature of evaporation (Camuffo 2010); the calculated wet-

4 bulb values presented in Table 2 represent the lowest theoretical temperatures that can be recorded from the evaporating stone surface throughout environmental conditions experienced during the experimental run.

7 Each experimental run lasted 8 hours. Weight readings and surface thermal images, 8 using the FLIR thermal camera, were collected manually at the beginning of each 9 experimental run and again at subsequent 10 minute intervals. The Optris PI160 thermal video camera collected data automatically and at a higher resolution with thermal snapshots programmed to be collected at $0.03 \mathrm{~Hz}$ (33 1/3 second intervals).

A TA9535 hotwire anemometer (Topac Inc., USA) was used to monitor the air velocity and flow volume across the stone block during the experiments with simulated airflow. Ten readings were performed at arbitrary times and taken approximately $30 \mathrm{~mm}$ from the centre of exposed surface of the sandstone block; the results are shown in Table 3.

\subsection{Results}

\section{$19 \quad 3.1 \quad$ Permeability data}

20 Permeability data from the surface of the Locharbriggs experimental block are shown 21 in Figures $4 a \& b$ and Tables $4 a \& b$. The mean surface permeability was $360.65 \mathrm{mD}$ and a positive skewness in the permeability distribution (Figure 4a and Table 4a) indicates that a large proportion of permeabilities are close to the mean value with a

24 limited number of higher permeabilities ( $~ 600 \mathrm{mD})$.

25 Summary statistics were also generated for each of the three beds (Table 4b). The 26 mean permeability for Bed A, Bed B and Bed C was 244, 569 and $368 \mathrm{mD}$, respectively. This permeability trend of Bed $B>B e d A>B e d C$ is also reflected in the minimum, median and maximum permeability values. Permeability data were mapped to produce an image of the variation in permeability across the stone surface (Figure $4 b$ ) revealing three distinct areas that appear to correspond to the different beds identified in the experimental block (see Figure 2d). 


\section{$2 \quad 3.2 \quad$ Bulk evaporative dynamics}

3 Information on the weight loss, moisture content, evaporation rate and mean surface 4 temperature for the bulk stone sample, throughout each of the experimental runs, is presented in Figure 5. It is important to note that data reported in this section represent aggregated change for the bulk sandstone sample and/or surface and thus masks surface variability. The impact of surface variability will be addressed later.

8 For all variables clear differences exist between each of the different simulated 9 environments and throughout the experimental run. The conditions of forced evaporation (that is, surface airflow, radiative heating and radiative heating with a surface airflow) do, however, experience broadly similar trends.

The simulated condition of radiative heating promoted the greatest evaporative loss a weight change of $39.8 \mathrm{~g}$ was observed due to moisture loss over the eight-hour experimental run. In comparison, a weight reduction of $35.5,34.0$ and $17.6 \mathrm{~g}$ was measured for the environments of radiative heating with a surface airflow, surface airflow and shade, respectively (see Figure 5A). The initial pore water content (or the capillary absorption coefficient) of the stone varied from $63.2-66.2 \%$. At the end of the experiments the bulk moisture content was 43.0, 20.6, 14.8 and $17.3 \%$ for conditions of shade, surface airflow, radiative heating and radiative heating with a surface airflow, respectively (Figure 5B).

21 During the shaded experiment, weight loss and thus the moisture content varied linearly. In contrast, under the three conditions of forced evaporation the measured change was non-linear; initially the rate of weight loss and the bulk moisture content changed relatively rapidly until a point in time when the rate of change began to slow.

The timing of this inflection point occurred first under conditions of radiative heating and a surface airflow after 120 minutes; after 160 minutes under conditions of surface airflow and also for radiative heating. The moisture content at the inflection point was between 30-31\% for the three simulated conditions of forced evaporation. Before the inflection point, moisture loss occurred more rapidly during the conditions 30 of radiative heating with a surface airflow than for radiative heating alone. After the 31 inflection point, however, moisture loss was more significant for conditions of radiative heating alone. 
1 The drying rate or the amount of moisture loss that occurs through the block surface 2 (140 x $105 \mathrm{~mm})$ per unit time - highlights more clearly the disparities between the

- The drying rate for the shaded experimental condition decreased rapidly during the initial 10 minutes of the experimental run, after which it remained constant - varying from 47-57 ml/day. From 300 minutes onwards the shaded condition exhibited the highest drying rate

- At the beginning of the surface airflow experiment the drying rate was 300 $\mathrm{ml} /$ day; this experienced a generally steady decline for 140 minutes, to 200 $\mathrm{ml} /$ day, after which the drying rate decreased rapidly until it remained between 15-20 ml/day

- The drying rate during radiative heating increased rapidly in the opening 60 minutes from $\sim 110$ to $300 \mathrm{ml} /$ day. The rate then fluctuated around $300 \mathrm{ml} / \mathrm{day}$ up to a time of 130 minutes, after which it significantly decreased (in a fashion similar to the surface airflow conditions)

- A similar rapid decrease also occurred under simulated conditions of radiative

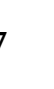

8
heating with a surface airflow, after 60 minutes. This simulated environmental
condition experienced the greatest overall drying rate of $446.4 \mathrm{ml} /$ day.

Average stone surface temperature (Figure 5D) change exhibits a high degree of variability between the different simulated environmental conditions:

- Again, the shaded condition displays the least amount of change, with temperatures increasing from 15 to $21^{\circ} \mathrm{C}$ over the eight hour experimental run

- Surface temperature during the surface airflow conditions remained between 15 and $17^{\circ} \mathrm{C}$ over the opening 160 minutes of the experimental run. The stone 5 then experienced an increase in temperature, up to $\sim 22^{\circ} \mathrm{C}$, above that 6 recorded for the shaded experiment. The timing of this increase appears to 7 correlate with the rapid reduction in the drying rate.

28 - The highest surface temperature $\left(52.4^{\circ} \mathrm{C}\right)$ and greatest temperature range $9\left(34.2^{\circ} \mathrm{C}\right)$ was recorded during radiative heating alone. The bulk surface temperature change during radiative heating also appears to be correlated 1 with changes in the drying rate. Initially the surface temperature rises rapidly 
as the drying rate increases, it then remains stable at $38-40^{\circ} \mathrm{C}$ until the drying rate decreases (at 130 minutes), at which point it rises again

- Mean surface temperature for conditions of radiative heating with a surface airflow also reflects the drying rate; temperatures for this environmental setting were, however, lower than that of radiative heating and the overall temperature change was not as dramatic.

These data provide an overview of the bulk sandstone block evaporative response to four sets of simulated environmental conditions. These results provide only a partial picture of the actual complexity of conditions associated with surface variability, which are further explored in the following section.

\subsection{Surface variability in evaporative dynamics}

Observations revealed that the stone surface exhibited spatial variability in evaporative dynamics throughout the experimental run. The stone surface displayed visual heterogeneity under conditions of forced evaporation; however, during the eight-hour experimental run simulating shade, the stone surface did not experience localised visual differences. The onset of the surface variation under forced evaporation was marked by a colour change (Figure 6) that was first apparent only in the medium-grained bed (Bed $B$ ). The timing of this visual surface dissimilarity differed between environmental conditions, occurring first, after 45 minutes, under the conditions of radiative heating with a surface airflow, after 60 minutes under radiative heating alone and after 90 minutes when subjected to just surface airflow.

This difference first emerged as a thin band in the centre of Bed $B$ that appeared lighter in colour (Figure 6); this band then widened progressively towards the edges of Bed $B$ at a rate that differed between each of the simulated environmental condition. The fine-medium bed (Bed A) was the next bed to display any visible colour change and then the fine bed (Bed C). But again the timing and rate of these visual surface changes varied depending on the environmental condition, so too did the observed pattern of drying - see Figure 7.

In addition to these visual observations, two-dimensional surface information (Figure 8) revealed localised temperature differences that appear to reflect material 
1 heterogeneity. The thermal surfaces presented show that temperature variations 2 were most apparent during the conditions of forced evaporation, indicating that the 3 highest temperatures, generally, occurred in Bed B and that Bed C experienced the 4 lowest temperatures. Interestingly, subtle thermal variations were observed during the shaded condition highlighting the presence of a faint band, which indicated higher temperatures (by $\sim 2^{\circ} \mathrm{C}$ ) in the location of Bed $\mathrm{B}$. The temperature difference between each of the beds varied throughout the experimental run and depending on the simulated environmental condition; the evolution of these thermal changes is presented in Figure 9.

During the shaded conditions the temperatures of Bed A and Bed B exhibited a similar trend, differing by $\sim 0.2^{\circ} \mathrm{C}-$ Bed $\mathrm{A}$ experienced higher temperatures (Figure $9 \mathrm{~A}$, Inset 1 ). Bed $C$ also follows the same trend but the temperatures are typically $0.4^{\circ} \mathrm{C}$ lower than Bed $\mathrm{B}$. Bed $\mathrm{C}$ was $\sim 0.5^{\circ} \mathrm{C}$ more than the ambient wet bulb temperature of $14.6^{\circ} \mathrm{C}$.

Under the conditions of a surface airflow (Figure 9B), the temperature of all beds decreased by around $0.5^{\circ} \mathrm{C}$ over the opening 10 minutes of the experimental run. Initially, Bed A experienced marginally higher temperatures $\left(<0.3^{\circ} \mathrm{C}\right)$ than Bed B. At around 110 minutes this trend reversed (Figure 9A, Inset 2), persisting until 150 minutes, after which the temperatures converged, fluctuating together, for the remainder of the experimental run.

21 The temperature of Bed $\mathrm{C}$ was $0.5-1.0^{\circ} \mathrm{C}$ lower than Bed $\mathrm{A}$ and $\mathrm{B}$ during the opening 22120 minutes and was marginally higher than the wet bulb temperature of $13.5^{\circ} \mathrm{C}$. The 23 temperature differential then increased as the temperatures of Bed $A$ and $B$ increased more rapidly; the maximum difference between Bed $C$ and the other beds was $\sim 2.0^{\circ} \mathrm{C}$, at 150 minutes. The temperature of Bed $\mathrm{C}$ then began to converge and at the 380 minute mark the temperatures of all beds were relatively stable, although Bed $\mathrm{C}$ was around $0.3-0.4^{\circ} \mathrm{C}$ lower (Figure 9B, Inset 3).

Conditions of radiative heating promoted rapid surface temperature increases in the first 30 minutes with the temperature thus being in excess of the wet bulb 30 temperature. During this time Bed A and B registered similar temperature profiles; 31 Bed $\mathrm{C}$, however, experienced higher temperatures, for example, after 15 minutes the temperature was $\sim 1.0^{\circ} \mathrm{C}$ higher than Bed $\mathrm{A}$ and $\mathrm{B}$ (Figure $9 \mathrm{C}$, Inset 4). The 
1 temperature difference between Bed $\mathrm{C}$ and Bed $\mathrm{A}$ and $\mathrm{B}$ was greatest between 130

2 to 160 minutes (Figure 9C, Inset 4) - by 190 minutes the temperatures all three beds became broadly similar and remained so for the remainder of the experimental run.

4 The conditions of radiative heating with a surface airflow produced the most complex temperature responses (Figure 9D). During this experimental run Beds $A$ and $B$ charted similar temperature profiles. The temperatures profiles of Beds A, B and C, over the first 90 minutes, were characterised by regular peaks and troughs (Figure 9D, Inset 6); these occur at 5 minute intervals and are due to the fan being switched off as the measurements are recorded - an issue relating to experimental design. Figure 9D, Inset 6 also displays the temperature divergence that occurs, after 50 minutes, as Bed $A$ and $B$ heat more rapidly than Bed $C$. At the end of the experimental run the temperature of $\mathrm{Bed} C$ is between $0.5-0.7^{\circ} \mathrm{C}$ lower than Beds $\mathrm{A}$ and $\mathrm{B}$.

\subsection{Discussion: Interpretation and insights on evaporative complexities}

Data presented here demonstrate that the rate of evaporation varies depending on environmental conditions and highlight the presence of small-scale evaporative variabilities that appear to be related to material heterogeneities associated with planar bedding. These results demonstrate the difference in surface microenvironments during evaporation and highlight the importance of materialenvironment interactions.

\subsection{Environmental conditions: bulk effectiveness and temporal variability}

Differences in the overall amount of evaporative loss between different environmental settings reflects how each simulated environment influences the fundamental factors necessary for evaporation to occur - that is, the supply of energy, the ability for water vapour to be removed from the surface and the ability of the material to transmit moisture to the surface to meet the evaporative demand.

The distinct differences exhibited by the conditions of shade and those of forced evaporation over the eight hour experimental runs, in terms of the temporal change in weight loss, moisture loss and drying rate (Figure 5A), reflect the different stages of 
1 evaporation. The traditional theory of drying of porous media typically distinguishes

2 three evaporative stages. Stage I is characterized by a high and relatively constant rate of moisture removal facilitated by connected hydraulic pathways and the capillary transport of moisture from depth to the evaporative surface (e.g. Van Brakel 1980; Siegesmund and Dürrast 2011). Breakdown of these hydraulic pathways marks the end of Stage I and the cessation of capillary driven evaporation. Stage II evaporation is limited by the rate at which the porous material (stone) can support the diffusive or vapour transport of moisture and is typically characterized by a significant reduction in evaporation rate (e.g. Hillel 1998; Rousset-Tournier et al. 2000; Hall and Hoff 2012). The end of Stage II and start of Stage III evaporation is not always acknowledged because the transition is gradual, unlike the sharp transition that characterises the switch from Stage I to Stage II. Stage III is characterized by the diffusive flux of water vapour from a subsurface vaporization plane, through a desiccated near-surface layer and out through the surface.

The linear change observed throughout the shaded experiment indicates Stage I evaporative loss - with water being transmitted to the material surface, under capillary forces, after which it changes to vapour and leaves the stone. The decrease in drying rate over the first ten minutes may reflect the loss of water, not held in pores, from the outer stone surface - as suggested by Rousset-Tournier et al. (2000). In contrast, the non-linear change in bulk properties (Figure 5A) observed during the conditions of forced evaporation reflects the transition from Stage I to Stage II evaporation (and then Stage III). An initial rapid decrease in moisture loss indicates Stage I evaporation with the progressive decrease in rates of loss, after the inflection point suggesting a transition to Stage II evaporation - that is, a disruption in hydraulic continuity between the stone surface and subsurface material and recession of the drying front to depth. This stage of evaporation reflects a transition from liquid (capillary) to vapour (diffusive) transport; this switch to a less efficient transport mechanism would explain the reduced rates of evaporative loss observed after the inflection point. The inflection point marking this transition occurs at the same moisture content ( $30-31 \%)$, a value that appears to correspond to the critical moisture content which increases with increasing material thickness (Tavukçuoğlu and Grinzato 2008) - the use of a different sample thickness, in the experiments, 
1 The link between the drying rate and the mean surface temperature demonstrates

2 the coupling that exists between stone temperature and moisture conditions (Figure

3 5) during evaporation and more generally. During Stage I evaporation, under surface

4 airflow conditions, the high drying rate promotes evaporative cooling, suppressing the mean surface temperature. The higher surface moisture content also acts to increase the heat capacity of the material, meaning that more energy is required to increase the temperature. However, the switch to Stage II evaporation, which is brought about by a decrease in surface moisture content, is marked by an increase in the mean surface temperature, which begins at around 150 minutes. This is likely to result in a reduction in evaporative cooling (as seen by a reduction in the drying rate) and a decrease in the heat capacity and thermal conductivity near the material surface. Similar processes also occur during conditions of radiative heating and radiative heating with a surface airflow.

14 Radiative heating was found to be the most effective environmental condition in 15 promoting evaporative loss producing the greatest overall weight change over the eight hour experimental run. The inflection point during this condition occurs after that of radiative heating with a surface airflow and at around the same time as that of a surface airflow; after the inflection point the drying rate is highest for conditions of radiative heating.

These observations are likely to be related to the effect temperature and airflow has on energy at the surface, the vapour pressure gradient and the nature of water within the pores. The presence of a surface airflow acts to circulate air above the material surface, removing water vapour, increasing the vapour pressure gradient and thus the potential for evaporation. This explains why evaporative loss was greater with a surface airflow than during the conditions of shade and why the inflection point during radiative heating with a surface airflow occurred before that in radiative heating alone. The observation that after the inflection point evaporative loss is greatest under radiative heating alone is related to the influence temperature has on the 29 diffusion of water vapour. Water vapour diffusivity increases with increasing temperature (Jabbro 2009), meaning that vapour can move more easily through the pore space - from a drying front at depth to the material surface - at higher temperatures. 
1 The environments simulated represent conditions commonly experienced by stone,

2 albeit greatly simplified. It needs to be remembered that, in reality, environmental conditions are complex and highly dynamic; over short periods of time a stone may undergo different combinations of heating (radiative and/or convective), cooling and surface airflows, which are likely to be of varying magnitude and frequency (c.f. Smith et al 2008; Smith et al. 2011b). Nevertheless, these data provide valuable insights into complex material / environment interactions.

\subsection{Spatial complexity: stone heterogeneity and possible hydraulic} interaction

11 The spatial differences - both visual and thermal - observed across the sandstone surface, during conditions of forced evaporation, appear to be related to material heterogeneity (bedding). More specifically, the differences are likely to relate to the influence varying pore space properties have on the differential timing, between material beds, of the transition between the stages of evaporation. Visual change is not apparent during conditions of shade, which is likely to be related to lower evaporation rates and the relatively short duration of the experimental run; subtle thermal differences are apparent (Figure 8) and may reflect varying evaporative rates from different surface regions. A conceptual diagram is presented in Figure 10 to chart the spatial changes observed for the bedded sandstone (Figure 10A) throughout the experimental run - explanations are offered below.

22 Initially, the stone surface is visibly wet and of a similar appearance (Figure 10B); 23 evaporation occurs at the material surface and is uniform across each of the beds. 24 Evaporation is controlled by external atmospheric conditions; water, driven by capillary forces, is transferred to the stone surface along hydraulically connected pathways - this is Stage I in the evaporative process. The lower temperatures experienced by Bed C during Stage I evaporation (see, for example, Figure 9B, the first 90 minutes) may be due to the smaller pore size with increased energy being required to liberate water from smaller pores because of the stronger capillary forces.

30 As such, the latent heat involved in the liquid-vapour phase change will be greater 31 and so too will be the degree of evaporative cooling (Camuffo 1998). 
1 After a period of time (that varies with external conditions) visual surface change 2 becomes apparent in Bed B - characterised by a thin band of lighter colour (Figure $10 \mathrm{C}$ ). This colour change is likely to be a manifestation of decreasing moisture at the surface of Bed B, which results in an increase in the diffuse scattering (or reflection) of light (c.f. Hall and Hoff 2012) - hence the lighter colour. Localised thermal variations (Figure $8 \mathrm{~B} \& \mathrm{C}$ ) reveal comparatively higher temperatures in Bed $\mathrm{B}$ that appear to correlate with the observed visual change and decreases in the bulk moisture content (Figure 5B; Figure 9B, Inset 3 ) and drying rate (Figure $5 \mathrm{C}$ ). This temperature variation may be due to a decrease in evaporative cooling; the reduction in the drying rate lends support to this suggestion. It could also be that the decrease in moisture content may influence the material thermal properties in such a way to promote an increase in temperature. These explanations are not mutually exclusive and it is likely that both factors are acting together. These changes may be an indication of a transition from Stage I to Stage II in the evaporative process in Bed B. This transition is characterised by a progressive reduction in surface moisture content, hydraulic continuity between the surface and depth is disrupted and the drying front recedes to a subsurface position. Subsequent moisture lost through the surface of Bed B must be transported by diffusion.

Visual surficial differences next became apparent in Bed A (Figure 10D) and then following this in Bed C (Figure 10E). The timing and rate of this change, in each bed, again varies depending on the simulated environmental condition being run. This difference in timing is reflected in the temperature profile of Bed C (see Figure 9, Insets 2, 5 and 6). The increasing difference in temperature between Bed $C$ and the rest of the surface is related to Bed $A$ and $B$ warming more rapidly (because of a switch to Stage II evaporation) and continued evaporation from Bed $C$ which suppresses the temperature (see also Figures $8 \mathrm{~B} \& \mathrm{C}$ ). The change is not homogenous in each bed, instead it occurs in patches (see Figure 7) that may be related to either small-scale variability within each bed or, possibly, uneven heating or uneven surface airflows. Again visual change is manifest as a changing colour and is likely to reflect the onset of Stage II in the evaporative process.

31 Differences in timing of visual and thermal changes are likely to be linked to the switch to Stage II evaporation, appear to be related to varying material properties. 
1 diameter $(0.75 \mu \mathrm{m})$ of this bed (Table $1 \mathrm{~b})$. Evaporation occurs first in pores with larger

2 radii because of the effect pore size has on the curvature of the meniscus and thus the vapour pressure difference between the pore and atmosphere (Camuffo 1984; respectively, which fits with the relative timing.

A key material parameter that governs the transition between evaporative stages is the width of the pore size distribution; the duration of Stage I evaporation increases with increasing width in the pore size distribution (Lehmann et al. 2008). The width of the pore size distribution for each bed ranged from $0.005 \mu \mathrm{m}$ to $250 \mu \mathrm{m}$ (Table $1 \mathrm{~b}$; Figure 1). Bed $C$ however experienced a more even distribution between micro- to macro-pores. Beds A and B exhibited similar pore size distributions and it may be that in these beds the differences are related to the effect pore size has on the specific surface area and the tenacity with which water is held within the pores.

Previous research, carried out on model soils, has shown that the presence of textural contrasts can initiate hydraulic coupling within the material (Shahraeeni and Or 2010). Although hydraulic coupling could not be monitored in these experiments, its occurrence is possible in heterogeneous porous stones during drying. This internal hydraulic interaction between different beds begins when the drying front recedes preferentially into the coarser grained bed, or Bed B (Figure 10C). This initiates a capillary pressure difference between Bed $B$ and the surrounding finergrained beds, Beds $\mathrm{A}$ and $\mathrm{C}$, encouraging flow into these beds (Lehmann and Or 2009) - a form of capillary pumping as described by Tsimpanogiannis et al. (1999). When the drying front in Bed $A$ recedes into the material, capillary induced liquid flow will only occur from Bed B to Bed C (Figure 10D). The presence of these material interactions during drying has a major impact on the distribution of moisture within stone yet they have not previously been considered in the stone decay literature. The identification and preliminary examination of these previously unconsidered evaporative complexities show that different regions of the same stone experience varying moisture dynamics during drying. As these appear to be related to heterogeneous properties associated with bedding, they demonstrate the importance varying material interactions can play over a small spatial scale. The outcome of these interactions on stone micro-environmental conditions cannot be inferred from ambient conditions alone and this supports the definition of microenvironment as the 
1 "boundary conditions at the surface and even inside the pores of a material and is

2 determined by the interaction of the material with its microclimate" (Ashton and

3 Sereda 1982: 82).

4 Data reported here provide empirical evidence to support the influence that small-

5 scale (sub-centimeter) structural and mineralogical variations can have on the rate of

6 moisture loss through evaporation and hint at the potential complexity in patterns of

7 bed-to-bed moisture transfer. These data also have wider significance for better

8 understanding of the potential for differential movement of contaminants such as salt

9 dissolved within moisture absorbed by stone and the development of related 10 weathering morphologies. Linked to this is the significance of data reported her for 11 better understanding of differential times of wetness in heterogeneous stone 12 (McCabe et al, 2013) and the implications of this for the operation of weathering 13 processes overtime and the associated development of divergent weathering 14 response (McCabe et al, 2015).

\section{Acknowledgements}

18 The authors wish to acknowledge the contribution made to the inception of this 19 project by the late Professor Bernard Smith. During the period of this research, $\mathrm{Dr}$ 20 Daniel McAlister was in receipt of post-graduate $\mathrm{PhD}$ funding from the Engineering 21 and Physical Sciences Research Council, UK (EPSRC). 


\section{References}

Ashton, H.E. and Sereda, P.J. 1982. Environment, Microenvironment and the Durability of Building Materials, Volume I, 49-65.

Barreira, E. and de Freitas, V.P. 2007. Evaluation of building materials using infrared thermography. Construction and Building Materials, 21, 218-224.

Bland, W. and Rolls, D. 1998. Weathering: an introduction to the scientific principles, New York: Oxford University Press.

Brüggerhoff, S., Wange, G., Morat, P., Le Mouël, J-L. and Perrier, F. 2001. First results of using combined mass and temperature measurements to study the water flow at the rockatmosphere interface. Journal of Cultural Heritage, 2, 117-132.

BSI. British Standards Institution 2007. BS EN 1936:2006. Natural Stone Test Methods: Determination of Real Density and Apparent Density, and of Total and Open Porosity. BSI: London.

Building Research Establishment (BRE) 2000. Locharbriggs Sandstone: Technical Data Sheet. http://projects.bre.co.uk/ConDiv/stonelist/locharbriggs.html (Accessed 20.01.16)

Camuffo, D. 1984. Condensation-evaporation cycles in pore and capillary systems according to the Kelvin model. Water, Air and Soil Pollution, 21, 151-159.

Camuffo, D. 1998. Microclimate for Cultural Heritage, Elsevier: Amsterdam.

Camuffo, D. 2010. The role of temperature and moisture. In: Camuffo, D., Fassina, V. and Havermans, J. (eds) Basic Environmental Mechanisms Affecting Cultural Heritage: Understanding Deterioration Mechanisms for Conservation Purposes. COST Action D 42: Chemical Interactions between Cultural Artefacts and Indoor Environment (EnviArt), 9-30.

Gayo, E., De Frutos, J., Palomo, A. and Massa, S. 1996. A mathematical model simulating the evaporation processes in building materials: experimental checking through infrared thermography. Building and Environment, 31, 469-475.

Goudie, A.S. and Viles, H.A. 1997. Salt weathering hazards, Chichester: John Wiley and Sons.

Grinzato, E., Ludwig, N., Cadelano, G., Bertucci, M., Gargano, M. and Bison, P. 2011. Infrared thermography for moisture detection: a laboratory study and an in-situ test. Materials Evaluation, January 2011, 97-104.

Hall , M.R. and Allinson, D. 2010a. Heat and mass transport processes in building materials. In: Hall, M.R. (ed) Materials for Energy Efficiency and Thermal Comfort in Buildings, Woodhead Publishing: Cambridge, 3-53.

Hall, M. R. and Allinson, D. 2010b. Evaporative drying in stabilized compressed earth materials using unsaturated flow theory. Building and Environment, 45, 509-518.

Hall, C. and Hoff, W.D. 2012. Water Transport in Brick, Stone and Concrete (2 ${ }^{\text {nd }}$ Edition), Spon Press: London.

Hillel, D. 1998. Environmental Soil Physics, Academic Press: San Diego.

Hyslop, E.K. and Alnornoz-Parra, L. 2009. Developing a future repairs strategy for a sandstone city: a petrographic investigation of building stone in Glasgow, Scotland. Materials Characterization, 60, 636-643.

Jabbro, J.D. 2009. Water vapor diffusion through soil as affected by temperature and aggregate size. Transport in Porous Media, 77, 417-428.

Lehmann, P. and Or, D. 2009. Evaporation and capillary coupling across vertical textural contrasts in porous media. Physical Review E, 80, 046318. 
Lehmann, P., Assouline, S. and Or, D. 2008. Characteristic length affecting evaporative drying of porous media. Physical Review E, 77, 056309.

Marica, F., Chen, Q., Hamilton, A., Hall, C., Al, T. and Balcom, B.J. 2006. Spatially resolved measurement of rock core porosity. Journal of Magnetic Resonance, 178, 136-141.

McCabe, S., McKinley, J.M. Gomez-Heras, M. and Smith, B.J. 2011. Dynamical instability in surface permeability characteristics of building sandstones in response to salt accumulation over time. Geomorphology, 130, 65-75.

McCabe, S., Smith, B.J., McAlister, J.J., Gomez-Heras, M., McAllister, D., Warke, P.A., Curran, J.M. and Basheer, P.A.M. 2013. Changing climate, changing process: implications for salt transportation and weathering within building sandstones in the UK. Environmental Earth Sciences, 69(4), 1225-1235.

McCabe, S., McAllister, D., Warke, P.A. and Gomez-Heras, M. 2015. Building sandstone surface modification by biofilm and iron precipitation: emerging block-scale heterogeneity and system response. Earth Surface Processes and Landforms, 40(1), 112-122.

McKinley, J.M., Warke, P., Lloyd, C.D., Ruffell, A.H. and Smith, B.J. 2006. Geostatistical analysis in weathering studies: case study for Stanton Moor building sandstone. Earth Surface Processes and Landforms, 31, 950-969.

Nachson, U., Weisbrod, N., Dragila, M.I. and Grader, A. 2011. Combined evaporation and salt precipitation in homogeneous and heterogeneous porous media. Water Resources Research, 47, W03513.

Pender, R.J. 2004. The behaviour of water in porous building materials and structures. Reviews in Conservation, 5, 49-62.

Prommas, R. 2011. Theoretical and experimental study of heat and mass transfer mechanism during convective drying of multi-layered porous packed bed. International Communications in Heat and Mass Transfer, 38, 900-905.

Rousset-Tournier, B. Jeanette, D. and Destrigneville, C. 2000. Stone drying: an approach of the effective evaporating surface area. In: (eds) Proceedings of the $9^{\text {th }}$ International Congress on Deterioration and Conservation of Stone, Venice, 629-635.

Sass, O. 2005. Rock moisture measurements: techniques, results, and implications for weathering. Earth Surface Processes \& Landforms 30: 359-347

Shahraeeni, E. and Or, D. 2010. Thermo-evaporative fluxes from heterogeneous porous surfaces resolved by infrared thermography. Water Resources Research, 46.

Siegesmund, S. and Dürrast, H. 2011. Physical and mechanical properties of rocks. In: Siegesmund. S. and Snethlage, R. (eds) Stone in Architecture: Properties, Durability $\left(4^{\text {th }}\right.$ edition), Springer: London, 97-226.

Smith, B.J. 2012. Weathering. In: Holden, J. (ed) An Introduction to Physical Geography and the Environment, Essex: Pearson, 185-214.

Smith, B.J., Srinivasan, S., Gómez-Heras, M., Basheer, P.A.M. and Viles, H.A. 2008. Experimental studies of near-surface temperature and moisture cycling and surface wetting of stone and its implications for salt weathering. In: Ottosen, L.M., Rrig-Dalgaard, I., Larsen, P.K., Brajer, I., Bøllingstoft, P., Marciniak, M. and Svane, M. (eds) Proceedings from the International Conference of Salt Weathering on Buildings and Stone Sculptures, Copenhagen, October 2008, 65-77.

Smith, B.J., Srinivasan, S., Gómez-Heras, M., Basheer, P.A.M. and Viles, H.A. 2011. Nearsurface temperature cycling of stone and its implications for the scales of surface deterioration. Geomorphology, 130, 76-82. 
Tavukçuoğlu, A. and Grinzato, E. 2008. Determination of critical moisture content level for porous materials by quantitative IR thermography. In: Łukaszewicz, J.W. and Niemcewicz, P. (eds) Proceedings of the $11^{\text {th }}$ International Congress on Deterioration and Conservation of Stone, Torun, Poland, 529-538.

5 Tsimpanogiannis, I.N., Yortsos, Y.C., Poulou, S., Kanellopoulos, N. and Stubos, A.K. 1999.

6 Scaling theory of drying in porous media. Physical Review E, 59, 4353-4365.

7 Van Brakel, J. 1980. Mass transfer in convective drying. In: Mujumdar, A.S. (ed) Advances in 8 Drying, Volume 1, Hemisphere: London, 217-268.

9 Whalley, W.B. and Warke, P.A. 2005. Weathering. In: Selley, R.C., Robin, L., Cocks, M. and 10 Plimer, I.R. (eds) Encyclopedia of Geology, London: Elsevier Academic Press, 581-590.

11 Warke, P.A. and Curran, J. 2010. Building stones of Northern Ireland. In: Curran, J., Warke, P.A., Stelfox, D., Smith, B.J. and Savage, J. (eds) Stone by Stone: a Guide to Building Stones in the Northern Ireland Environment, Appletree Press: Belfast, 47-101.

14 Yiotis, A.G., Salin D., Tajer, E.S. and Yortsos, Y.C. 2012. Analytical solutions of drying in 15 porous media for gravity-stabilized fronts. Physical Review E, 58, 046308. 
Figure Captions

Figure 1: Pore size distribution graphs for each of the three beds present in the experimental block, Bed A, Bed B and Bed C.

Figure 2: A) Image of the bedded Locharbriggs Sandstone block when dry, B) Image of sandstone block when wet, C) surface area of the sandstone beds, and D) regular grid, with 1 centimeter spacing, used for collection of the permeametry measurements.

Figure 3: Schematic diagram illustrating the experimental set-up designed to monitor the variable evaporative flux from bedded sandstone under the following environmental conditions: A) Shade; B) Surface airflow; C) Radiative heating; and, D) Radiative heating and a surface airflow - the protective cardboard surround is not shown.

Figure 4: A) Histogram of measured permeability distribution, B) Air permeability surface (contour) map produced from measured data using OriginPro 8. Permeability values are reported in millidarcies $(\mathrm{mD})$.

Figure 5: Aspatial (bulk) data collected during the evaporation experiments from bedded Locharbriggs sandstone showing: A) Cumulative weight loss; B) Changing moisture content; C) Drying rate; and D) Mean surface temperature. A-C were produced using gravimetric data; $\mathrm{D}$ was produced from thermal data acquired using the FLIR camera.

Figure 6: Diagram illustrating the onset of the observed visual surface heterogeneity in the bedded sandstone sample and the surface appearance at selected times at later stages in the experimental run.

Figure 7: Diagram illustrating variability in visible surface wetness during conditions of forced evaporation at selected times throughout the experimental run.

Figure 8: Two-dimensional thermal surfaces (captured using the FLIR thermal camera) showing thermal variability observed during experimental conditions of: A) Shade; B) Surface airflow; C) Radiative heating; and, D) Radiative heating with a surface airflow. The timing and temperature scale of each image is different; a standardised scale would mask differences related to material heterogeneity and the same was not used because rates of evaporation varied under different simulated conditions 
1 Figure 9: High-resolution thermal information (collected at $33 \frac{1}{3}$ second intervals using the 2 Optris camera) showing the thermal evolution of a point/pixel from the centre of each unit 3 (Beds A, B and C) during the simulated experimental conditions of: A) Shade; B) Surface 4 airflow; C) Radiative heating; and, D) Radiative heating with a surface airflow. (Graphical 5 insets provide higher resolution insights into the thermal differences between the units at 6 times of interest - information provided in text).

7

8 Figure 10: Conceptual diagram identifying the variability of moisture dynamics related to 9 bedding exhibited throughout the experimental run. 


\section{TABLES AND CAPTIONS}

Table 1a: Summary of structural and mineralogical properties of Locharbriggs Sandstone

\begin{tabular}{lll}
\hline Property & Value & Comment / Data Source \\
\hline Age & Permian $(300-250 \mathrm{Ma})$ & \\
Primary Mineralogy & Quartz and Hematite & Stone Database Project \\
Apparent Density & $1992.69 \mathrm{~kg} / \mathrm{m}^{3}$ & Stone Database Project \\
Porosity accessible to $\mathrm{H}_{2} \mathrm{O}$ & $18.20-24.90 \%$ & BRE 2000 \\
Porosity accessible to $\mathrm{Hg}$ & $15.58 \%$ & Original measurements \\
Mean Pore Diameter & $0.18 \mu \mathrm{m}$ & Original measurements \\
Average Air Permeability & $57.58 \mathrm{mD}$ & Adamson, pers comm.. \\
Saturation Coefficient & $0.65-0.68$ & BRE 2000 \\
Water Absorption Capacity & $5.7 \%$ & BRE 2000 \\
\hline
\end{tabular}

Table 1b: Pore characteristics for the three beds in the Locharbriggs sample block

\begin{tabular}{|c|c|c|c|}
\hline Property / Characteristic & Locharbriggs Bed A & Locharbriggs Bed B & Locharbriggs Bed C \\
\hline Connected porosity & $16.37 \%$ & $20.56 \%$ & $15.58 \%$ \\
\hline $\begin{array}{r}\text { Micro }<5 \mu m \text { (\% of total } \\
\text { porosity) }\end{array}$ & $15.40 \%$ & $20.30 \%$ & $47.70 \%$ \\
\hline $\begin{array}{r}\text { Macro }>5 \mu m(\% \text { of total } \\
\text { porosity })\end{array}$ & $84.60 \%$ & $79.70 \%$ & $52.30 \%$ \\
\hline$<0.01 \mu m$ & $0.77 \%$ & $0.02 \%$ & $1.53 \%$ \\
\hline 0.01 to $0.1 \mu \mathrm{m}$ & $2.99 \%$ & $2.78 \%$ & $6.96 \%$ \\
\hline 0.1 to $1.0 \mu \mathrm{m}$ & $5.66 \%$ & $7.33 \%$ & $14.20 \%$ \\
\hline 1.0 to $10 \mu \mathrm{m}$ & $11.85 \%$ & $22.70 \%$ & $64.61 \%$ \\
\hline 10 to $100 \mu m$ & $75.89 \%$ & $64.79 \%$ & $10.02 \%$ \\
\hline$>100 \mu m$ & $2.84 \%$ & $2.38 \%$ & $2.68 \%$ \\
\hline Specific surface area & $0.74 \mathrm{~m}^{2} / \mathrm{g}$ & $0.53 \mathrm{~m}^{2} / \mathrm{g}$ & $1.58 \mathrm{~m}^{2} / \mathrm{g}$ \\
\hline Tortuosity & $10.02 \mu \mathrm{m}$ & $14.82 \mu \mathrm{m}$ & $26.36 \mu \mathrm{m}$ \\
\hline Average pore diameter & $0.40 \mu \mathrm{m}$ & $0.75 \mu \mathrm{m}$ & $0.18 \mu \mathrm{m}$ \\
\hline Apparent density at $1.4 \mathrm{psi}$ & $2.20 \mathrm{~g} / \mathrm{ml}$ & $2.08 \mathrm{~g} / \mathrm{ml}$ & $2.20 \mathrm{~g} / \mathrm{ml}$ \\
\hline Real density & $2.63 \mathrm{~g} / \mathrm{ml}$ & $2.62 \mathrm{~g} / \mathrm{ml}$ & $2.61 \mathrm{~g} / \mathrm{ml}$ \\
\hline
\end{tabular}

Table 2: Ambient laboratory conditions for each experimental run

\begin{tabular}{lllll}
\hline Simulated Conditions & $\begin{array}{l}\text { Ambient } \\
\text { Temperature } \\
\left({ }^{\circ} \mathbf{C}\right)\end{array}$ & $\begin{array}{l}\text { Ambient } \\
\text { Relative } \\
\text { Humidity }(\%)\end{array}$ & $\begin{array}{l}\text { Barometric } \\
\text { Pressure } \\
(\mathbf{m b a r s})\end{array}$ & $\begin{array}{l}\text { Wet Bulb } \\
\text { Temperature } \\
\left({ }^{\circ} \mathbf{C}\right)\end{array}$ \\
\hline Shade & 23.2 & 37 & 1026 & 14.6 \\
Airflow & 22.6 & 34 & 1027 & 13.5 \\
Radiative heating & 25.1 & 45 & 1023 & 17.3 \\
$\begin{array}{l}\text { Radiative heating and } \\
\text { airflow }\end{array}$ & 24.7 & 43 & 1021 & 16.6 \\
\hline
\end{tabular}


Table 3: Air velocity and flow volume during experiments with simulated airflow

\begin{tabular}{lcccccc}
\hline Conditions & \multicolumn{3}{c}{ Air Velocity (m/s) } & \multicolumn{3}{c}{ Airflow Volume (I/s) } \\
& $\mathbf{N}$ & Mean & Range & N & Mean & Range \\
\hline Surface airflow & 10 & 0.68 & $0.34-1.74$ & 10 & 2.44 & $1.07-3.64$ \\
Radiative heating with & 10 & 0.76 & & 10 & 1.97 & $1.31-3.74$ \\
surface airflow & & & & & & \\
\hline
\end{tabular}

Table 4a: Summary permeability statistics for the experimental Locharbriggs sandstone block

\begin{tabular}{lc}
\hline Statistics & Value \\
\hline Number of data points & 120 \\
Mean & 360.65 \\
Standard deviation & 150.70 \\
Coefficient of variance & 0.42 \\
Maximum value & 933 \\
Upper quartile & 415.50 \\
Median & 339 \\
Lower quartile & 263 \\
Minimum value & 148 \\
\hline
\end{tabular}

Table 4b: Summary permeability statistics for each of the three beds

\begin{tabular}{lccc}
\hline Statistics & $\begin{array}{c}\text { Locharbriggs Bed A } \\
\text { (fine to medium) }\end{array}$ & $\begin{array}{c}\text { Locharbriggs Bed B } \\
\text { (medium) }\end{array}$ & $\begin{array}{c}\text { Locharbriggs Bed C } \\
\text { (fine) }\end{array}$ \\
\hline Number of data points & 40 & 20 & 60 \\
Mean & 244 & 569 & 368 \\
Standard Deviation & 56.10 & 215 & 69.50 \\
Coefficient of variance & 0.23 & 0.38 & 0.19 \\
Maximum value & 363 & 933 & 589 \\
Upper quartile & 279.50 & 725.50 & 415.50 \\
Median & 231 & 474.50 & 361 \\
Lower quartile & 205.50 & 402.50 & 322.50 \\
Minimum value & 148 & 326 & 232 \\
\hline
\end{tabular}




\section{FIGURES AND CAPTIONS}

Figure 1: Pore size distribution graphs for each of the three beds present in the Locharbriggs experimental block, Bed A, Bed B and Bed C.
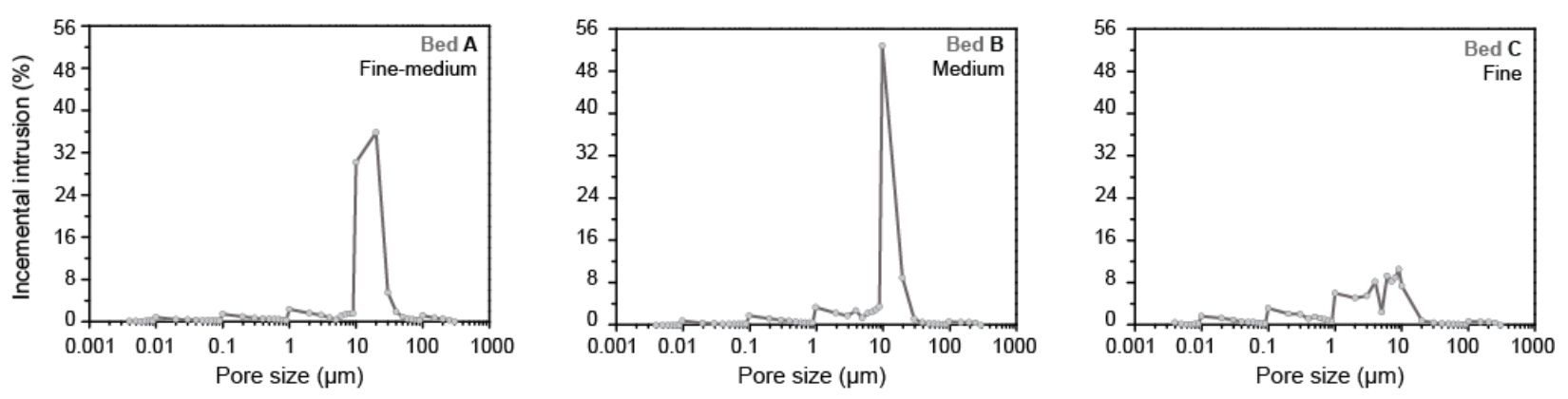

Figure 2: A) Image of the bedded Locharbriggs Sandstone block when dry, B) Image of sandstone block when wet, C) surface area of the sandstone beds, and D) regular grid, with 1 centimeter spacing, used for collection of the permeametry measurements.

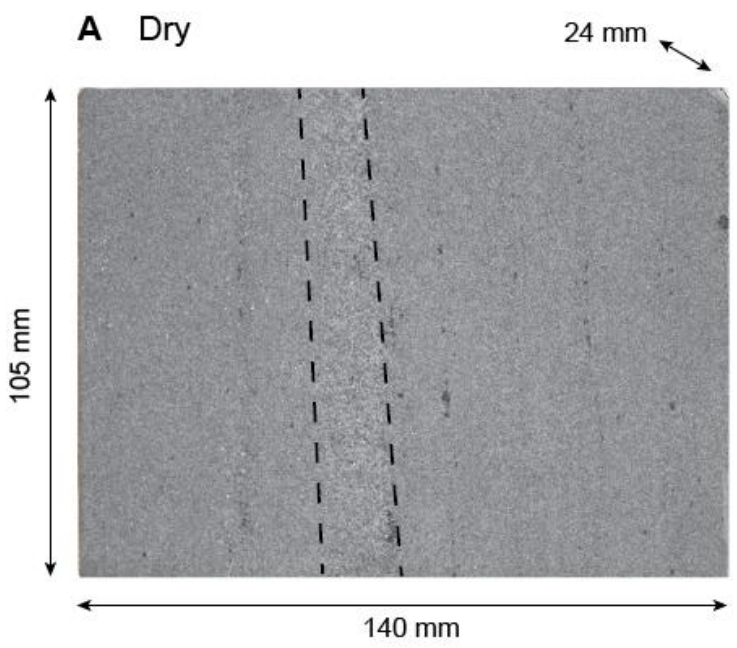

B Wet

C Different units (surface area)

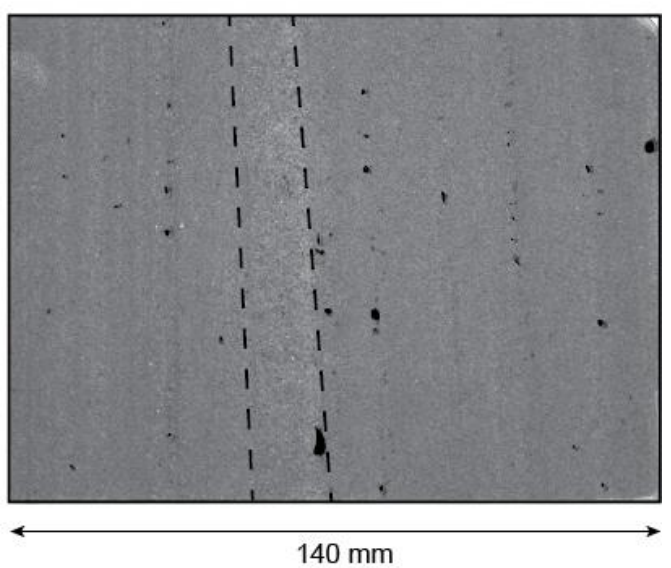

D Permeametry grid
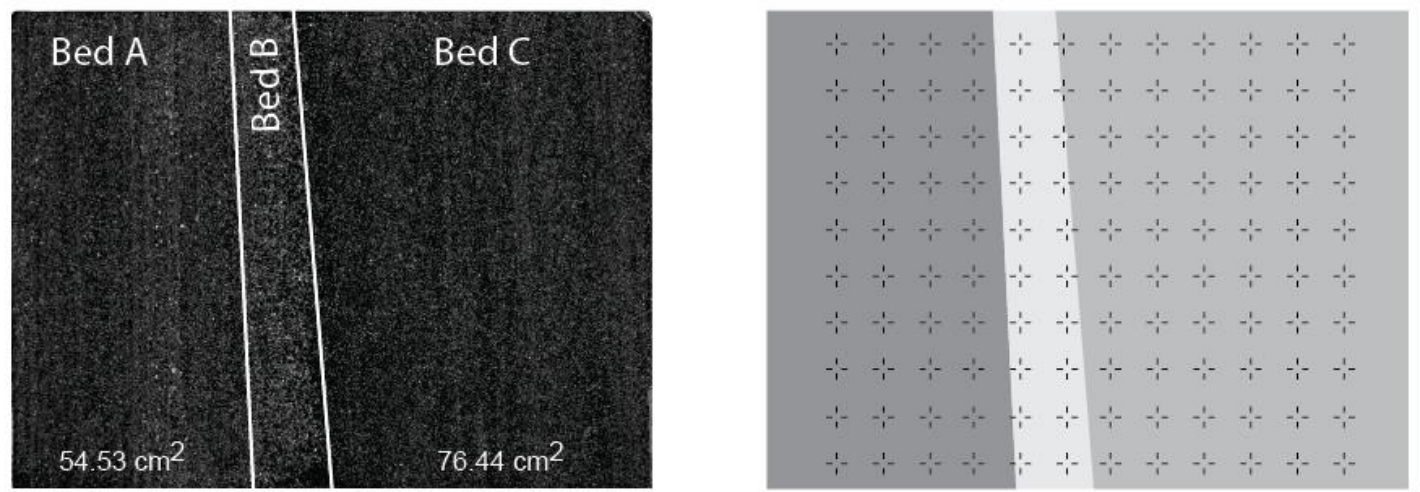

$16.02 \mathrm{~cm}^{2}$ 
Figure 3: Schematic diagram illustrating the experimental set-up designed to monitor the variable evaporative flux from bedded sandstone under the following environmental conditions: A) Shade; B) Surface airflow; C) Radiative heating; and, D) Radiative heating and a surface airflow - the protective cardboard surround is not shown.

\section{A Shade}

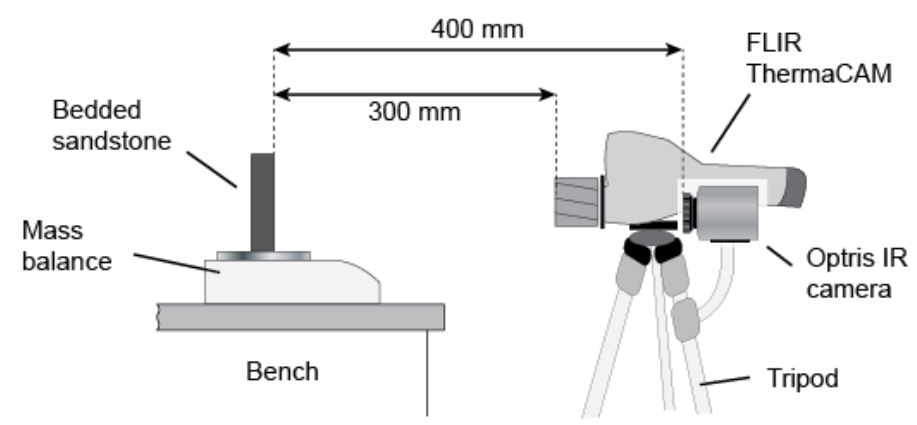

C Radiative heating

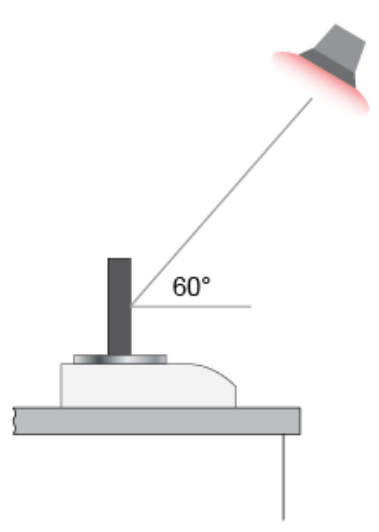
$500 \mathrm{~W}$ halogen lamp - $400 \mathrm{~mm}$ from stone

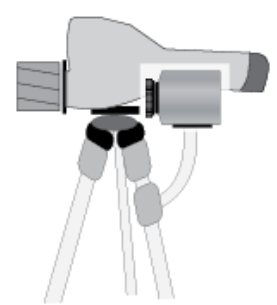

B Surface airflow

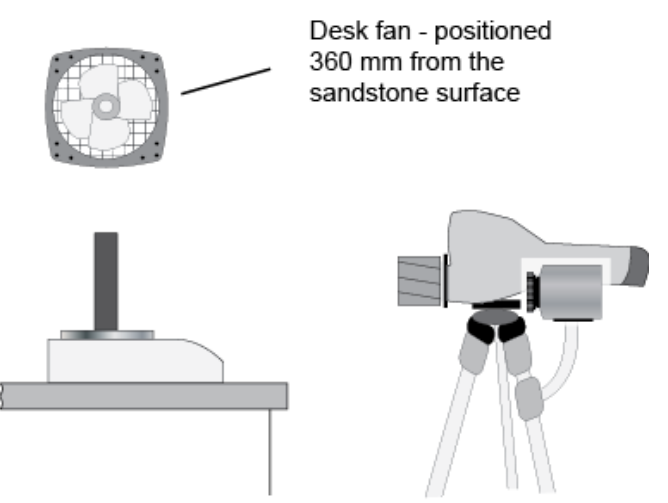

D Radiative heating and surface airflow
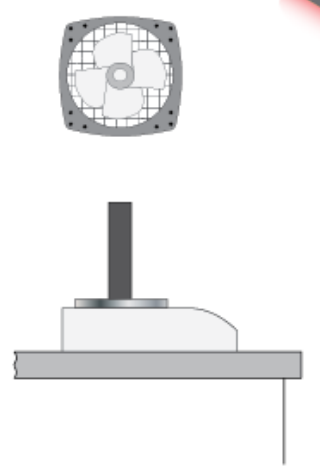

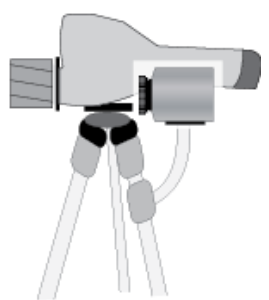


Figure 4: A) Histogram of measured permeability distribution, B) Air permeability surface (contour) map produced from measured data using OriginPro 8. Permeability values are reported in millidarcies $(\mathrm{mD})$.

A Permeability histogram

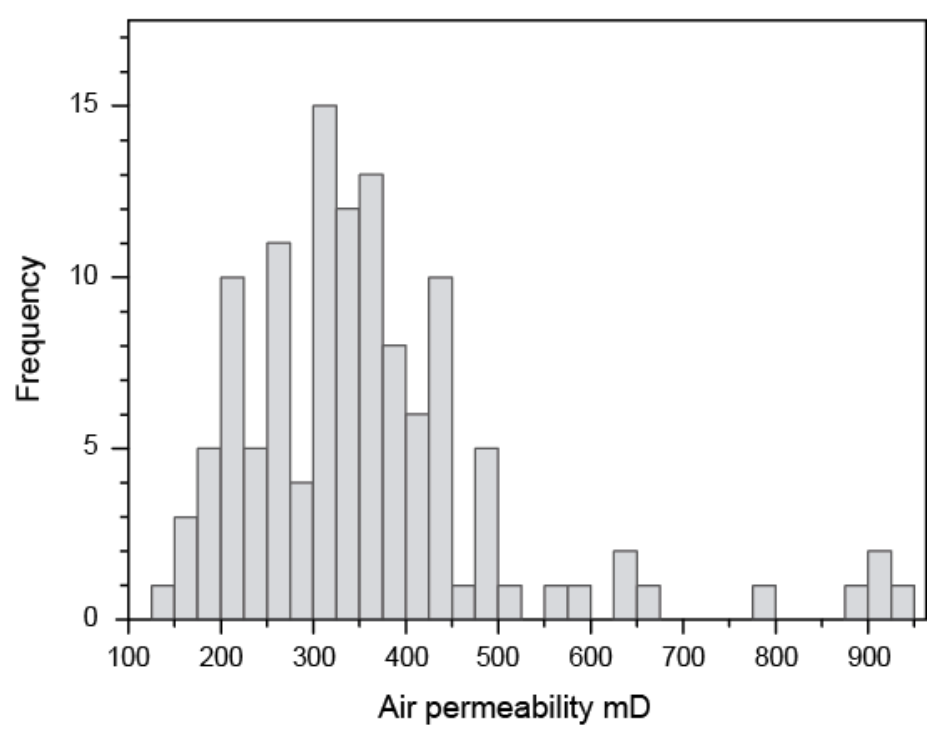

B
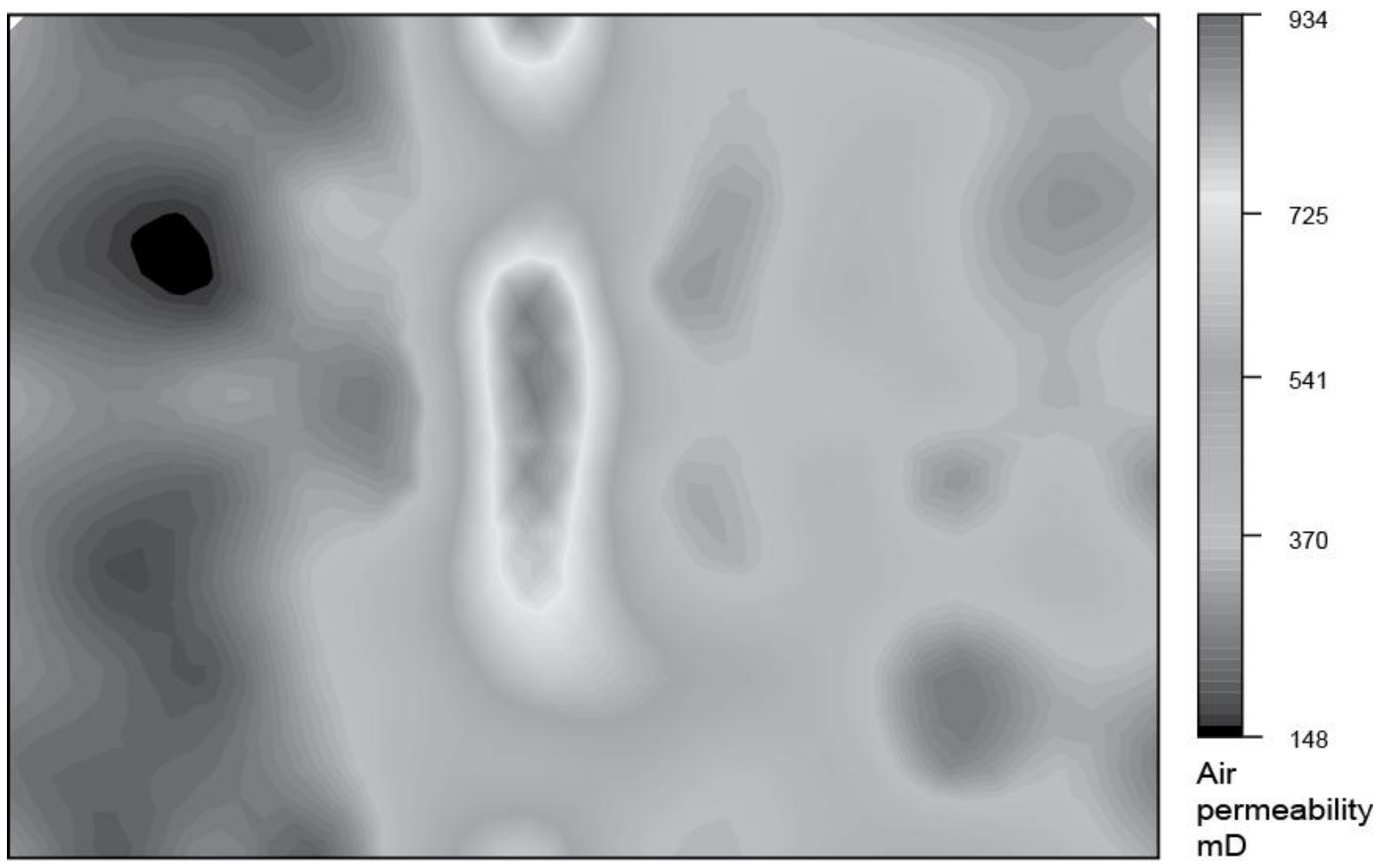
Figure 5: Aspatial (bulk) data collected during the evaporation experiments from bedded Locharbriggs sandstone showing: A) Cumulative weight loss; B) Changing moisture content; C) Drying rate; and D) Mean surface temperature. A-C were produced using gravimetric data; $D$ was produced from thermal data acquired using the FLIR camera.


Shade - - Radiative heating

Airflow $\quad-\quad--$ Radiative heating and airflow 
Figure 6: Diagram illustrating the onset of the observed visual surface heterogeneity in the bedded sandstone sample and the surface appearance at selected times at later stages in the experimental run.

Time at which visual surface dissimilarity becomes apparent

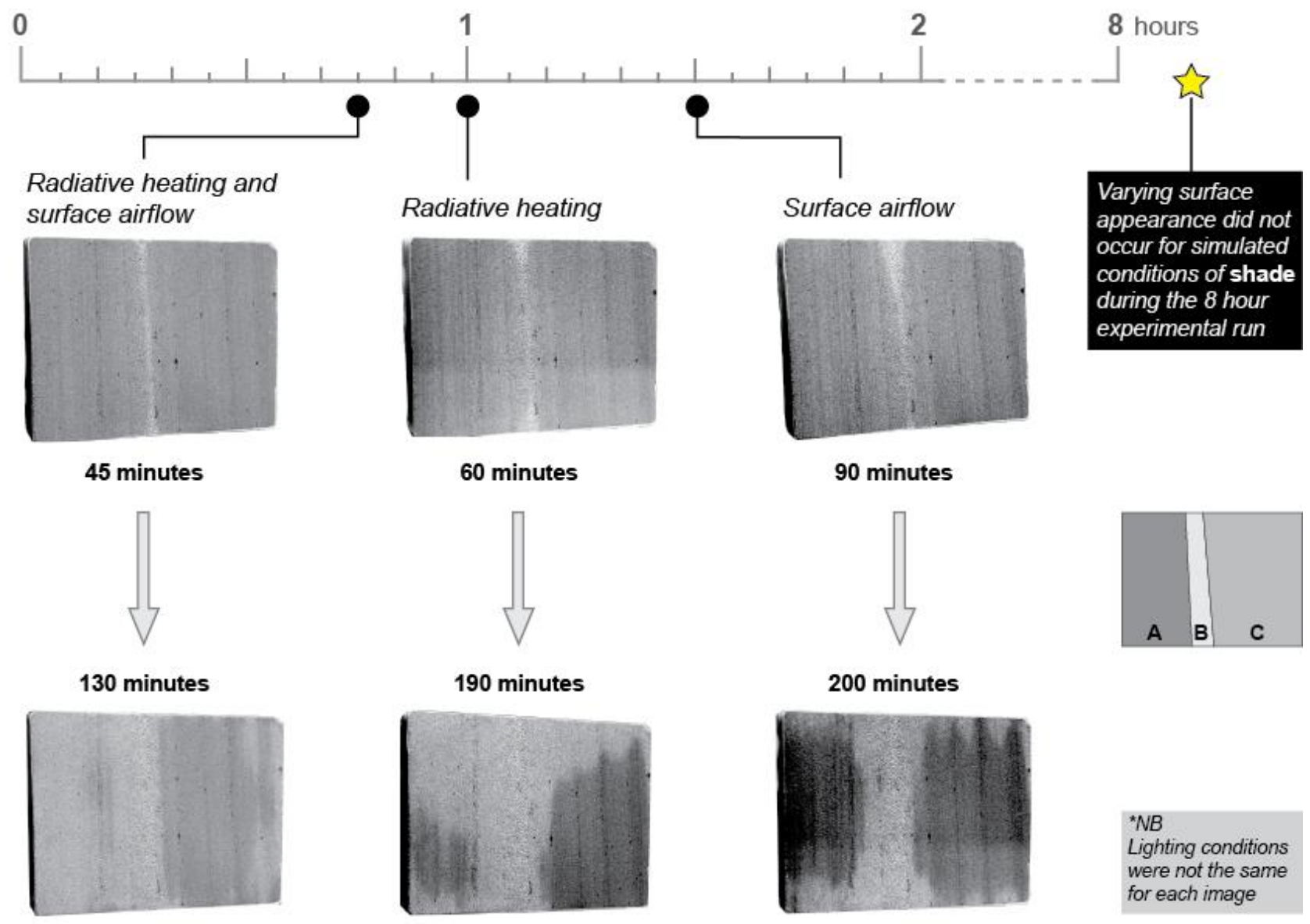

Surface appearance at a later stage in the experimental run 
Figure 7: Diagram illustrating variability in visible surface wetness during conditions of forced evaporation at selected times throughout the experimental run.

\section{Surface airflow}

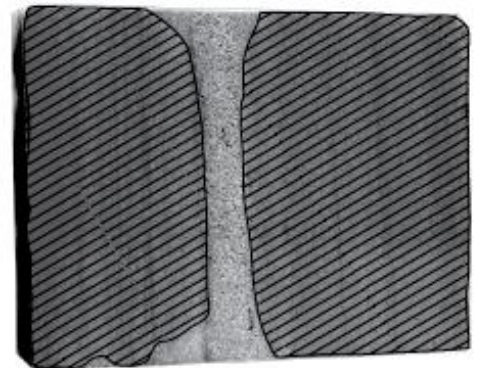

120 minute

\section{Radiative heating}



100 minute



140 minute

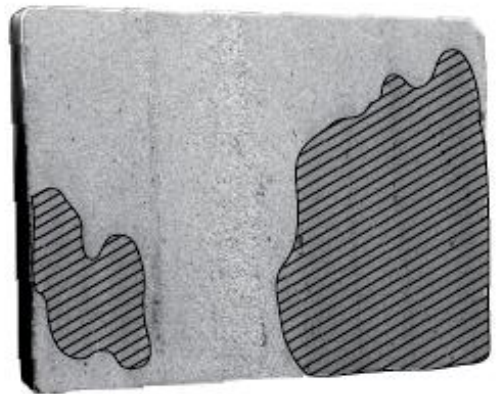

150 minute

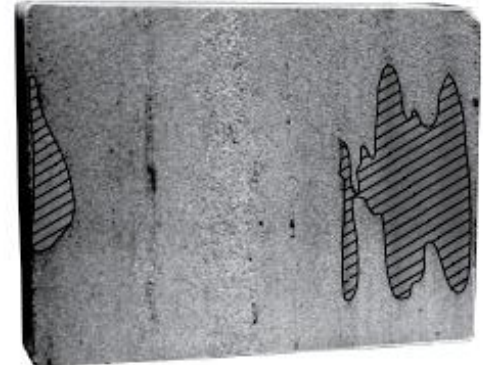

170 minute



170 minute

Radiative heating with surface airflow



50 minute



75 minute

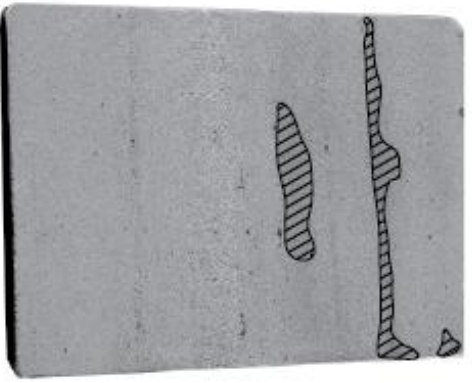

85 minute

Visibly wet surface 
Figure 9: High-resolution thermal information (collected at $33 \frac{1}{3}$ second intervals using the Optris camera) showing the thermal evolution of a point/pixel from the centre of each unit (Beds A, B and C) during the simulated experimental conditions of: A) Shade; B) Surface airflow; C) Radiative heating; and, D) Radiative heating with a surface airflow. (Graphical insets provide higher resolution insights into the thermal differences between the units at times of interest - information provided in text).

A Shade



C Radiative heating
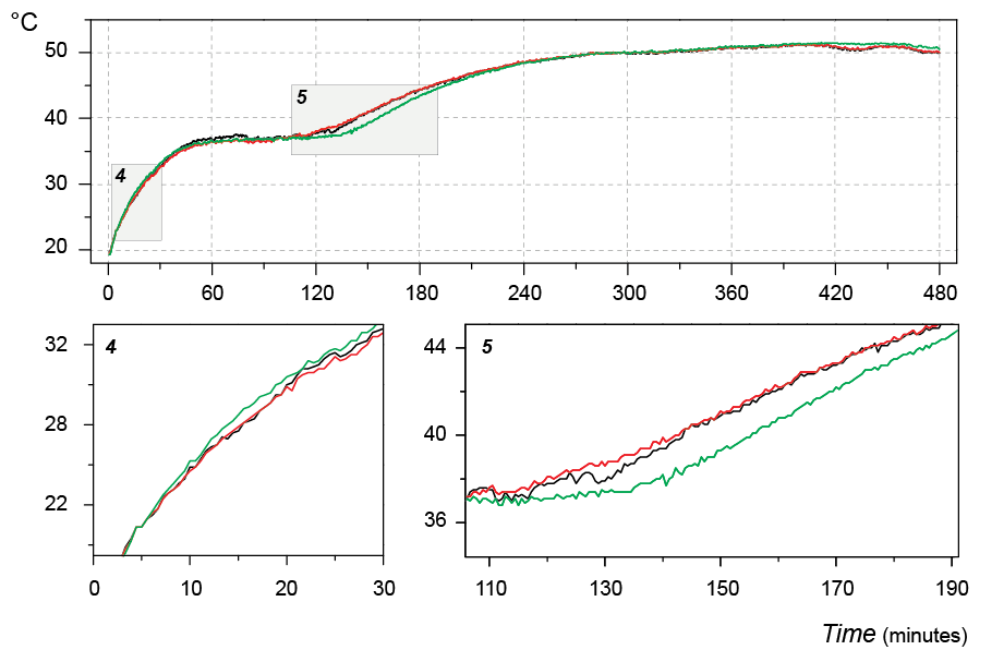

B Surface airflow


Measured point/pixel

()

Unit A

น

Unit B

mon

D Radiative heating with surface airflow
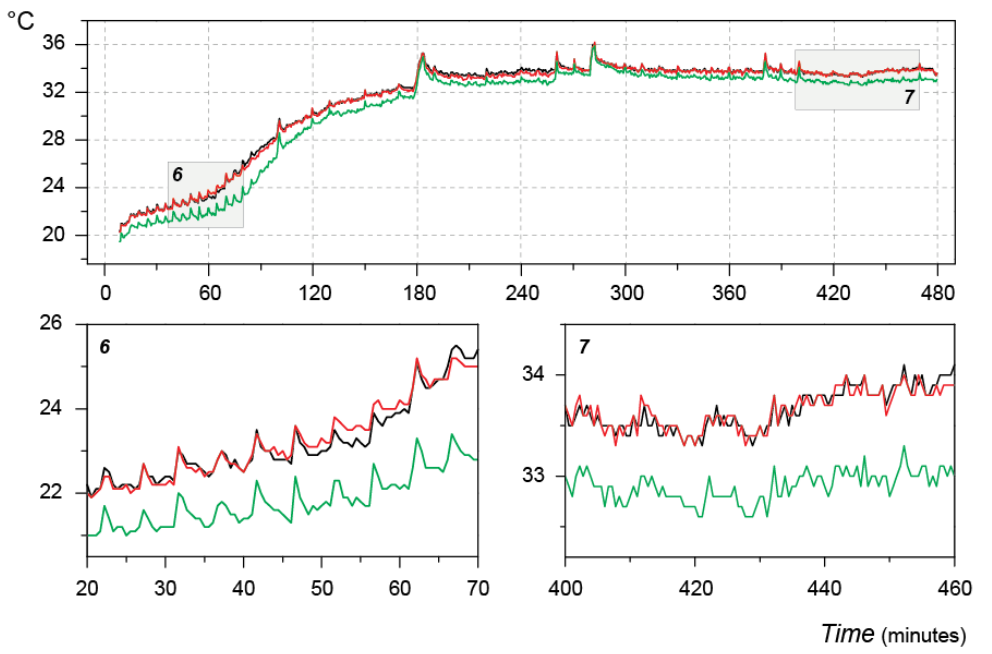

Unit C

$\sim$

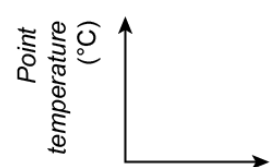

Time (minutes)

*NB The $x$-and $y$-axes of each graph are at 
Figure 10: Conceptual diagram identifying the variability of moisture dynamics related to bedding exhibited throughout the experimental run.

A Heterogeneous porous stone

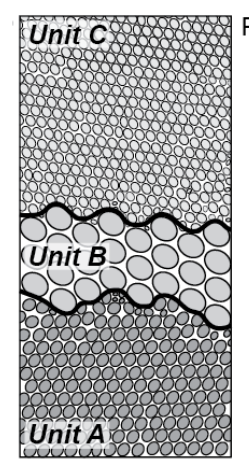

B Onset of evaporation

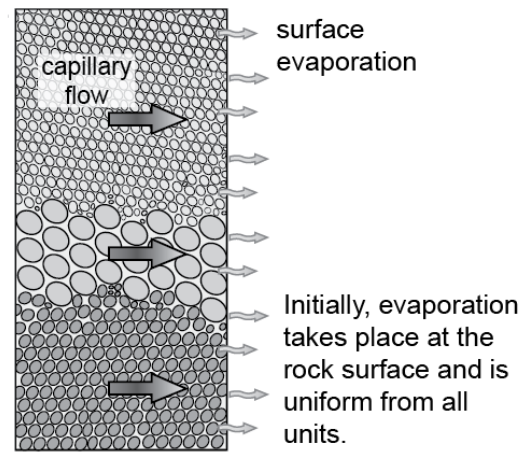

C Varying evaporative dynamics I



D Varying evaporative dynamics II

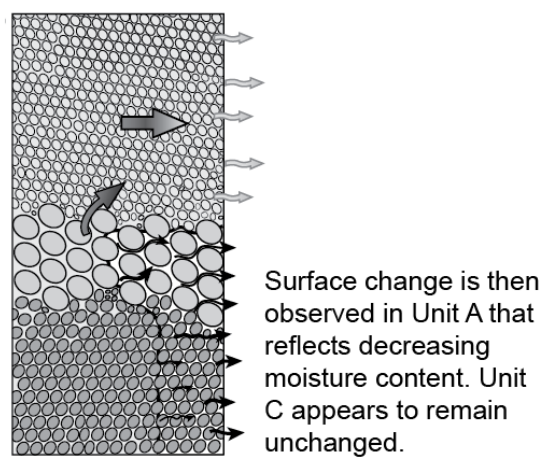

E Varying evaporative dynamics III

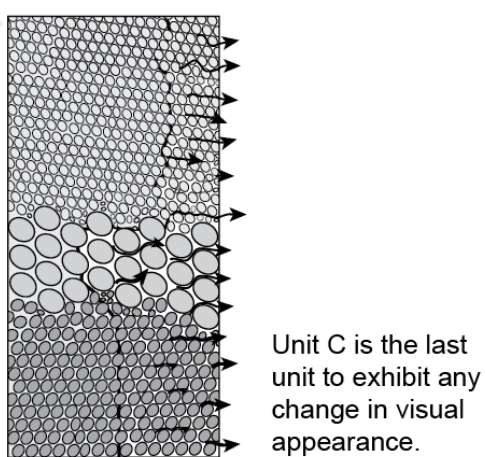

